\title{
Neokantismo, valores e razão discursiva: aproximações da metodologia jurídica com a axiologia política kantiana
}

\author{
Newton de Oliveira Lima ${ }^{1}$ \\ DOI 10.20399/P1982-999X.2016v1n1pp92-108
}

\begin{abstract}
Resumo: O neokantismo enquanto corrente de pensamento filosófico do Direito desenvolveu-se como método de conhecimento jurídico que buscou por uma intuição fenomenológica prescrever valores jurídicos. A reviravolta linguístico-pragmática na filosofia em meados do século XX ocasionou a substituição do neokantismo jurídico por uma metodologia linguística sobre o Direito dentro de um procedimento discursivo justificador dos direitos humanos como valores fundamentais (liberdade, igualdade, bem comum) e de uma racionalidade procedimental que volta a Kant como defesa do Estado de Direito. Buscaremos mapear a justificação discursiva e kantiana do Direito a partir do pensamento de Ricardo Terra e sua abordagem dos valores jurídicos como objetos linguísticos, o que abre caminho para uma nova metodologia jurídica baseada em valores construídos argumentativamente e de acordo com os princípios da razão kantiana.
\end{abstract}

Palavras-chave : neokantismo ; valores ; razão discursiva

\begin{abstract}
The neokantianism as a philosophical school of thought of Law developed as legal knowledge method that searched for a phenomenological intuition prescribe legal values . The linguistic- pragmatic turn in philosophy in the mid- twentieth century led to the replacement of the legal neokantianism by a linguistic methodology on the Law within a justifying discourse procedure of human rights as core values (liberty, equality, common good) and a procedural rationality who returns to Kant as a defense of State of Law. We will seek to map the discourse and Kantian justification of Law from the thought of Ricardo Terra and its approach to legal values as linguistic objects, paving the way for a new legal methodology based on constructed values arguably and according to the principles of kantian reason.
\end{abstract}

Key-words : neokantianism; values; discursive reason

$1 . O$ contexto de surgimento da teoria dos valores e o papel do neokantismo

A teoria valorativa moderna (Axiologia) assomou no contexto da Filosofia como uma estruturação conceitual do idealismo alemão, na vertente subjetiva de Hermann Lotze, o qual proclamou o princípio de que: “o valor vale.” Segundo Jonhannes Hessen (1980), essa visão idealista, desenvolvida por Scheler, Hartmann, Meinong etc, é centrada na determinação do valor como um objeto supra-temporal e supra-espacial, de modo a não existir, mas apenas ser, tal qual os entes matemáticos, que em sua estrutura apriorística, formalista e, nesse sentido aqui impingido, ideal, são co-naturais ao espírito subjetivo em geral e apreendidos para uns pela razão, como simples objetos lógicos (formalismo neokantiano) ou como objetos da pura sentimentalidade (intuicionismo scheleriano e ontologismo hartmanniano).

\footnotetext{
${ }^{1}$ Professor Adjunto, lotado no Departamento de Ciências Jurídicas da UFPB. Doutor em Filosofia pelo Programa Integrado de Pós-Graduação em Filosofia da UFRN-UFPE-UFPB. Mestre em Direito pela UFRN.
} 
Para o senso comum do "realismo ingênuo" a assertiva de que algo pode ter ser, porém não existir é paradoxal e até contraditória. Todavia, para compreender isto, basta imaginar-se o seguinte, exemplificando a partir da Matemática: os números quer os pensemos ou não, são em si; como se sabe, passam os séculos e eles continuam a ser tais quais sempre foram; quer sejam representados espacialmente ou não, sua estrutura é a mesma. A existência é irrelevante para a Matemática. O homem é que, uma vez existindo, consegue apreendê-los, se deixar de pensá-los, nem por isso deixarão de ser.

Analogamente se procede com os valores: quer os homens queiram ou não, exercitem ou não exercitem, a justiça será sempre uma relação de igualdade e proporcionalidade entre as pessoas.

Conforme Hessen (1980), Meinong forneceu as bases para tal Axiologia idealista, quando formulou sua 'Teoria dos Objetos', a qual, em síntese, apregoa haver 4 categorias de objetos: ideal(é mas não existe), natural(está no tempo-espaço), cultural(temporal mas não espacial), psíquico(somente temporal).

Observe-se que ideal, nessa ordem de considerações do idealismo axiológico, difere do conceito de ideal para os idealistas hegelianos (os quais viam na Idéia uma realidade absoluta e transcendente, e originadora do mundo natural), ou dos kantianos (para os quais a idéia seria um produto da mente, como na visão de senso comum que se tem da mesma).

Os valores foram incluídos pelos idealistas de várias vertentes, os gnoseológicos (intuicionistas, ontologistas, subjetivistas), na categoria da idealidade. Os culturalistas, não concordando com isso, incluem-nos dentre os objetos culturais. Os empiristas, naturalistas, positivistas, colocam-nos entre os objetos naturais e asseveram sua supressão face à materialidade unitária da realidade empírica que para eles envolve todos os entes, inclusive o valor. Os subjetivistas afirmam-nos estruturas componentes do psiquismo.

Dessarte, as correntes da teoria axiológica, inicialmente de cunho idealista, diversificou-se em variegadas concepções até mesmo radicalmente contrárias ao idealismo; este, entretanto, jamais desapareceu das lides filosóficas e, embora se mesclando a outras vertentes de pensamento, continua a figurar de modo incisivo na exploração dos estudos da Axiologia.

Para a acepção clássica de uma teoria dos valores à Scheler, o valor como ideal transcendental possui tais caracteres: possuir ser, mas não existência; e que pode ser apreendido racional e emotivamente pelo homem, e que por sua infinita possibilidade de 
concretização, porquanto a idealidade é infinitamente capaz de concretizar-se, o valor não se limita aos simples liames do real conhecido, mas abre-se num plano de possibilidade de existência concreta, plano este que não pode conter-se nos meandros da realidade conhecida: a essência de toda autêntica estimativa exige como pressuposto de seu ser a transcendência, que é a transposição necessária do real, dada a impossibilidade de nele concretizar-se plenamente o valor como ideal.

O neokantismo, no início do século $\mathrm{XX}$, transforma a teoria dos valores em culturalismo, isto é, os valores passam a possuir um caráter ontológico dentro da cultura e suas manifestações históricas, como expressa Hans Rickert apud Hessen (1980, p.32930)

Do jogo das forças inorgânicas nasce, de facto, alguma coisa de novo e de diferente delas, a vida orgânica; do organismo eleva-se o psíquico e de suas conexões nasce o mundo das normas. Finalmente, sobre este, sobre o mundo do dever-ser, levanta-se o mundo dos valores, o reino da espiritualidade e da Cultura. E este reino, com suas próprias leis, tende para a perfeição que, apesar de todos os nossos erros e desvios se torna sempre reconhecível como um fim ideal que domina toda a existência. Além disso, esta construção da Realidade por extratos encaminha-se para as Idéias como fundamento e fim último do Universo...Assim, no último fundamento deste deve acharse também oculta uma causa do Espírito e da vida espiritual.

Um dos aspectos mais importantes frisados pelos neokantianos foi o jurídico, representado principalmente pelo jusfilósofo alemão da metade do século XX, Gustav Radbruch, discípulo de Rickert, para o qual os fundamentos neokantianos da Filosofia do Direito enveredaram a pesquisa do fenômeno jurídico calcados nos seguintes fatores: 1- Busca de um conceito a priori do direito, capaz de atuar como unificador, sob sua definição, da multiplicidade das aplicações dos pressupostos normativos do direito. 2- A construção de tal conceito somente é possível a partir da noção de um poder nomotético (ordenador e revelador do espírito subjetivo) em relação à cultura, percebendo a racionalidade ética dos fins axiológicos, uma incidência da teleologia da Cultura.

O fato é que para os neokantinos existe uma "filosofia da consciência", entendida como tal pelo conceito kantiano de poder de projeção de normas como expressão do "Reino dos Fins", com a categoria nomotética (propagadora de normas) organizadora da Cultura que satisfaz a subjetividade com padrões de cognição correlacionados às estruturas de pensamento formalístico e preenche tais categorias com a atividade do pensamento racional-ordenador. 
Ernst Cassirer, um dos principais neokantianos da primeira metade do século $\mathrm{XX}$, indica que a fundamentação do Estado e do Direito encontra no mito a base de projeções que necessita a fim de deflagrar a possibilidade de ordem social, assim, no modo de ser da mitologia grega, a ordem estatal se baseava na cosmologia e na vontade do destino como proclamação da ordem superior sobre os humanos.

Cassirer refaz o itinerário do Estado desde a Antiguidade, passando pela idéia da polis na cidade Estado, recoloca o problema do valor da justiça em Platão e seu ideal de República, onde está presente a possibilidade de virtudes coletivas e de uma tríade de valores - o justo, a temperança e a coragem como atributos do homem político.

O Estado Moderno é apresentado por Cassirer como sendo vinculado ao sistema de legalidade, a legitimação decorrendo da dominação da lei sobre o cidadão pelo poder conferido por esse mesmo ao Estado, no fundamento do contratualismo moderno Cassirer encontra a valorização burguesa do indivíduo, ponto no qual ele aponta a base da esquematização kantiana da teoria do Estado com a tese de que o Estado encontra-se fundamentado no dever de proteção à autonomia do sujeito e que essa autonomia funda o contrato que origina o Estado.

A idéia de um Estado legal racional,esposada não apenas por Cassirer mas por Weber e sua teoria da legitimidade legal-racional como legitimação do Estado na modernidade, perfaz uma base perfaz se entender que uma legitimação do Estado em valores religiosos ou morais na Modernidade revela-se problemática na medida em que a impossibilidade de uma fundamentação absoluta de caráter metafísico se dá, Hobbes observou isto ao fundamentar o Estado Moderno numa base prescritiva e normativa, conforme aponta Cassirer (1961,p.217). A grande contraposição do Estado Moderno como calcado no Direito Público é ao privado-individual-exclusivo, que se funda na ordem medieval da autoridade eclesiástica e não na ordem pública de uma justiça construída pelo debate e pela exposição dos conflitos em público.

Cassirer recorre a Kant para encontrar a possibilidade de fundamentar a ação política nos âmbitos público e privado na Modernidade. Para Cassirer, a noção de autonomia colocada por Kant assoma como central para se entender o problema da liberdade - o núcleo de uma acepção de liberdade é a possibilidade de um sujeito que põe a si e ao mundo. Diz Cassirer (1961, p.348-49):

Segundo Kant, a liberdade é equivalente à autonomia. Não significa "indeterminismo", e ainda menos significa um tipo especial de determinação. Significa que a lei a que obedecemos nas nossas acções não nos é imposta do exterior, mas que o sujeito moral 
dita a si próprio essa lei. Na sua exposição da sua teoria, Kant previne-nos constantemente contra um mal-entendido fundamental. A liberdade ética, afirma ele, não é um facto, mas um postulado. Não é um gegeben, mas aufgegeben; não é um dom da natureza humana; é, antes, uma tarefa, e a mais árdua tarefa que o homem pode impor a si mesmo. Não é dada, mas pedida; é um imperativo ético. Realizar este pedido torna-se especialmente difícil em tempos de crise social quando a derrocada de toda a vida pública parece iminente.

Esse núcleo da Política calcado na dignidade e na autonomia do indivíduo é a contribuição da teoria da liberdade de Kant para a teoria dos valores políticos modernos, onde os antigos valores virtuosos da República romana, defendidos por Cícero, por exemplo, ou mais modernamente por Maquiavel, são retomados por Kant de um modo racional, um pressuposto racional e transcendental para a Política e a fundamentação do espaço público, o qual não pode ser desprezado, negado ou suprimido, sequer pelo processo sócio-econômico de reificação do indivíduo que o capitalismo impõe.

\section{Kant e o pensamento sobre o Estado Moderno}

O movimento de volta a Kant de um ponto de vista axiológico-político implica o reconhecimento do caráter individualista e, ao mesmo tempo, republicano, do pensador alemão. O Estado de Direito para os neokantianos, assim como para Kant, era a mais valiosa forma de assegurar as estimativas da justiça e da segurança; As agruras da II Guerra Mundial levaram a uma volta ao pensamento político de Kant, Radbruch (1971, p.21) expressou-o muito bem quando disse:

Tenemos que buscar la justicia, pero al mismo tiempo tenemos que mantener la seguridad jurídica, que no es más que um aspecto de la misma justicia, y reconstruir um Estado de Derecho que satisfaga a ambas ideas em la medida de lo posible.La democracia es ciertamente um bien precioso, pero el Estado de Derecho es como el pan de cada dia, como el água potable y el aire que se respira; y lo mejor de la democracia es precisamente eso: que es la única forma de gobierno apropriada para garantizar el Estado de Derecho.

A fundamentação racional da proteção ao sujeito levada a cabo por Kant implica de um ponto de vista político em um individualismo, no sentido da defesa do valor supremo como sendo a individualidade, como aponta Berlin (1981, p.147):

(...) Mas se, como bem afirmou Kant, todos os valores tornam-se valores pelos atos livres dos homens, e são desse modo chamados enquanto assim permanecem, não há valor mais elevado que o indivíduo. Portanto, fazer isso é coagir os homens em nome de 
algo menos final do que eles mesmos - é curvá-los à minha vontade ou a alguma ânsia particular de outrem, em favor de sua felicidade, benefício, segurança ou conveniência. Viso a algo desejado (por qualquer motivo, não importa quão nobre) por mim ou por meu grupo, para o qual estou usando outros homens como meio. Mas isto é uma contradição do meu conhecimento dos homens, isto é, dos fins em si mesmos. Todas as formas de adulterar os seres humanos, de pegá-los e moldá-los aos nossos padrões, contra a sua própria vontade, todos os controles e condicionamentos do pensamento, tudo isso é uma negação do que há de homem no homem e em seus valores finais.

Kant, consoante Berlin (1981, p.147), insere-se na tradição do individualismo liberal e, conforme à teoria de Berlin, sua liberdade política é uma liberdade negativa ${ }^{2}$, onde se imiscui de uma ação forçada, pelo contrário, é o Estado que deve respeitar o indivíduo e suas disposições.

Kant, segundo Berlin (1981, p. 102), se afasta da tradição de Spinoza e Hobbes que nega o valor da individualidade e da liberdade subjetiva, defende não apenas o esclarecimento, mas a autonomia. Não basta seguir a autonomia burguesa assegurada pelo Estado Moderno, porém é na motivação da racionalidade autônoma que se constrói a liberdade que possibilitará a construção de todos os valores, inclusive os do espaço público, do uso público da razão contra todas as tiranias, presentes na história da Modernidade em seus personagens individualistas absolutistas ou antiéticos e autoritários tais como Napoleão, Robespierre etc.

O que se traduz num valor político que se forma numa liberdade coletiva na possibilidade de uma liberdade construída republicanamente (publicamente e legalmente, no sentido kantiano de republicanidade política) e não apenas

\footnotetext{
${ }^{2}$ Kant indica a possibilidade de uma razão crítica e na sua tarefa de fundamentação da realidade social e política, ao proteger o indivíduo como base da dignidade humana, coloca a sistemática racionalidade a serviço dos objetivos da liberdade negativa do Estado. Berlin observa a liberdade negativa como cerne de uma concepção protetiva do indivíduo, já a liberdade positiva como faculdade de ação. Ora, nesse sentido Berlin indica a liberdade política como garantia ao indivíduo, e mais, como determinação do Estado de fazer o bem comum se justificar pela adesão à racionalidade e à dignidade. $\mathrm{O}$ sistema de direitos de Kant inclui, por isso, o direito à crítica ao Estado. O sistema de direitos implica na manutenção da dignidade dentro da soberania estatal, mas sem a impossibilidade de uma crítica cabal ao Estado. Esse paradoxo kantiano aproxima-o de Berlin, pois a liberdade positiva que Berlin requer é corrigida pela liberdade negativa de Kant e dos constitucionalistas em geral, quanto ao aspecto de uma limitação ao Estado. Diz Berlin (1981, p.152-153): "Minha defesa da liberdade irrestrita pode algumas vezes, prima facie, não harmonizar-se com a defesa da liberdade irrestrita feita por outra pessoa; mas a solução racional de um problema não pode colidir com a solução igualmente verdadeira de um outro problema, pois duas verdades não podem ser incompatíveis do ponto de vista da lógica; portanto, uma ordem justa precisa, em tese, ser discernível - uma ordem cujas normas possibilitem soluções corretas para todos os problemas que possam vir a surgir em seu âmbito (...) Racionalidade é conhecer as coisas e as pessoas pelo que elas são (...)". Nessa passagem de Berlin observa-se a necessidade de reconhecimento da liberdade positiva, de fazer, de ação, ao passo que em Kant, de poderia identificar uma passagem nitidamente vinculada ao sistema de limitações racionais à "liberdade natural".
} 
egoisticamente, no projeto capitalista de mercado competitivo. Conforme Berlin (1981, p.151-152):

Aqueles que acreditavam na liberdade como num autogoverno racional mais cedo ou mais tarde com certeza iriam refletir a respeito de como isso se aplicaria não apenas à vida interior de um homem, mas também ao relacionamento com outros membros de sua sociedade. Mesmo os mais individualistas dentre eles - E Rousseau, Kant e Fichte certamente começaram como individualistas- chegaram a um ponto em que se indagaram a si mesmos se era possível existir uma vida racional não apenas para o individuo, mas também para a sociedade, e, em caso positivo, de que forma poderia ela ser conseguida. Desejo ser livre para viver minha vontade (ou meu "eu real") ordena, mas outros também o desejam. Como evitar conflitos com as vontades dos outros ? (...) Um Estado racional (ou livre) seria um Estado governado por leis que todos os homens racionais acatariam livremente; (...)

Construir uma racionalidade coletiva indica um caminho para a superação das desigualdades. Na verdade, a razão implica um compartilhamento de possibilidades existenciais a todos.

Para que o Estado seja o que deve ser - a esfera pública onde se processa a política como discurso e como ação e cuja finalidade é o valor do bem coletivo, é preciso que haja um discurso político influenciando o discurso jurídico dentro do horizonte de ação que leve em conta a tarefa de mediação dialética exercida nas instituições (no âmbito do Estado) sobre os conflitos sociais, que no fundo são conflitos de valores, isto é, todo o discurso jurídico é discurso sobre valores e discurso político, segundo Kant (2010, p.79-81), não pode haver política sem Direito e também o contrário, só que limitando as finalidades políticas ao âmbito do espaço constitucional e à ética pública.

Se há o discurso com base em finalidades a serem atingidas pelo Estado - os valores, principalmente e prioritariamente os assegurados na Constituição republicana (ideal de um sistema político para Kant), então, o enquadramento da função política está garantida.

Sem autoconsciência e finalidade, sem a diferenciação sujeito-objeto, o homem insere-se na ontologia constituída - não diferenciado, insere-se na relação constitutiva dominante, a qual suprime toda dialética e transforma o homem em um ser alienado de suas múltiplas possibilidades existenciais. Esse alerta à autonomia do sujeito é a obra da crítica de Kant ao determinismo da liberdade (Spinoza), ao paternalismo político, ao coletivismo social, ao materialismo, ao ateísmo e ao irracionalismo sem freios do 
mercado através de uma possível doutrina intervencionista do Estado sobre a questão da pobreza a partir de uma aplicação do parágrafo 49 da "Doutrina do Direito" (KANT, 2005).

O Estado realiza-se pela realização concomitante do indivíduo. O limite da ação do Estado é precisamente o reconhecimento da liberdade do indivíduo a partir da sua concepção política, Humboldt (2002) já dissera isso em 'Os limites da ação do Estado'.

A função de mediação dos valores é prestada pelo Estado enquanto a própria possibilidade de se constituir na esfera pública preconizada por Kant (2005, p.272), que admite explicitamente a capacidade de crítica ao próprio Estado através do direito à crítica pelo uso público da razão, embora se deva respeito à legislação constituída pelo Estado soberano. Para Kant (2009, p.225) a principal forma de governo é a republicana, dado que:
A. Lei e liberdade sem poder (anarquia)
B. Lei e poder sem liberdade (despotismo)
C. Poder sem liberdade nem lei (barbárie)
D. Poder com liberdade e lei (república)

Kant indica a possibilidade mesma do uso público da razão como capacidade de crítica por parte do cidadão. Há uma possibilidade de cidadania ativa no pensamento republicano kantiano. Na verdade, a aposta kantiana na democracia, republicanismo e na razão crítica são instrumentos de resgate da possibilidade de por valores no espaço público pela construção discursiva e pública.

Duas perguntas são cruciais: 1) Há sentido em se estudar a filosofia política de Kant na atualidade, ou seja, o que Kant pode dizer sobre o momento da conjuntura política contemporânea e, 2) O que Kant pode dizer ao contexto brasileiro, em que sentido ele nos coloca a par da problemática política no Brasil.

Primeiramente, se observarmos a queda do "Muro de Berlim" em 1989 e a necessidade de uma redefinição da ordem política no mundo, o papel de uma regulação internacional das instituições é reconstruído e redimensionado em nível cosmopolita isso implicou que a retomada do pensamento político kantiano, desenvolvido na 'Paz Perpétua', foi recolocado como o principal projeto político de nível internacional. A própria concepção de uma federação de nações nos moldes kantianos foi reformulada na representação da Onu. A possibilidade de uma defesa cosmopolita de direitos humanos, 
a luta pela dignidade humana em diversas matizes no âmbito de formações culturais diferenciadas é a bandeira de uma retomada na contemporaneidade do pensamento político kantiano, após se observarem as cruezas que as concepções coletivistas do socialismo, do nazi-fascismo fizeram à Humanidade.

Uma contribuição da Filosofia brasileira à tradição kantiana foi a coletânea “Kant e a Instituição da Paz”, coordenada pelo Prof. Valério Rohden, onde diversos kantianos pátrios e estrangeiros versam interpretações sobre o pensamento política acerca da idéia de República, Cosmopolitismo, Democracia, Pacifismo etc., onde se colocam linhas hermenêuticas que atualizam e descobrem novos pontos de incidência na contemporaneidade do pensamento político de Kant.

Outra acepção que resgata o pensamento de Kant é a que se insere na tradição de uma defesa da Constituição e da legalidade jurídico-política, voltada à proteção do povo e ao sistema de uma eticidade objetiva que defende a dignidade humana e o espaço público como base de uma democracia constitucional. Daniel Perez coordenou um grupo de pesquisa, e mantém estudos continuados, na Filosofia política de Kant no diálogo com autores como Maquiavel, Hobbes etc., procurando uma ponte que satisfaça as complexas exigências da politicidade atual.

\section{Concepção democrática e discursiva da ética kantiana por Ricardo Terra}

Conseguir superar as inclinações imediatas (não mediadas pela razão), subjetivismo, emocionalismo, intuição vulgar, desejo espontâneo e inconsequente, eis o objetivo da ética deontológica kantiana. A forma universal da moralidade como objetivo da razão expressa não somente a racionalidade formal em Kant, mas a possibilidade da razão crítica, a metafísica da razão especulativa é transformada em confrontação com a experiência e desta força de choque emerge a impossibilidade do não conflito: todo o confronto de posições é posto pela própria crise da razão. Para a tradição que entende os valores e, dentre estes, o valor da justiça, como perceptíveis e exprimíveis apenas sentimentalmente como Hume, Shafestebury, entre outros, não há como fundamentar uma validade universal da justiça, pois 'Se houvesse um amor universal entre todas as criaturas humanas, ele se manifestaria do mesmo modo' (HUME, 2005, p.154). Pelo raciocínio humeano, portanto, não ocorre a possibilidade de um entendimento público com base na razão e conseguintemente no discurso público, porém mediante sentimentos comuns, a ainda assim de modo impreciso, incongruente. 
Kant pretendeu apreender o moral como racional-conceitual, a finalidade ética como dever e o querer como possibilidade de corresponder a um juízo universalmente válido. A ideia de moralidade em Kant é a própria expressão transcendental do fundamento de toda liberdade que como lei ética universal é a verdade do imperativo construído pela razão que se impõe à realidade humana, embora essa seja sua autora pelo princípio da autonomia, expresso na Terceira Seção da 'Fundamentação da Metafísica dos Costumes' (KANT, 2008).

Contrariamente aos neokantianos que buscaram nas formas culturais a expressão das idéias de valor como o fez Miguel Reale no Brasil, a tradição ortodoxa kantiana resgatada atualmente, busca uma pureza interpretativa de Kant no sentido de valorizar a autonomia dos sujeitos, a publicidade e a razão discursiva como marcos de construção de valores no espaço democrático.

Nesse último aspecto insere-se filósofo kantiano brasileiro Ricardo Terra, o qual fomenta o pensamento kantiano no Brasil através do debate com correntes neoiluministas como a de Habermas e da inserção no Brasil da tradição kantiana mais ortodoxa, H. Paton, A. Wood, H. Allisson, O. Höffe etc.

Terra, na década de setenta, escreve uma Tese de Doutoramento que hoje é um marco no resgate dos estudos kantianos no Brasil, "A política tensa. Idéia e realidade na filosofia da história de Kant", defendida precisamente em 1981. A partir de seu longo e minucioso trabalho, ocorre a retomada dos estudos kantianos no Brasil, empreendidos em outras vertentes (linguística, moral, estética) por filósofos igualmente importantes como Zeljko Loparic, Gérard Lebrun, Valério Rohden, dentre outros, que culminam por formar a 'Sociedade Kant' em fins da década de 90 do século passado.

Terra segue a análise da filosofia política kantiana vinculando-a ao pensamento platônico, interpretando o sentido ideal da Constituição sem considerações de ordem empírica (TERRA, 1995, p.21), pois para ele: "Kant transforma a idéia platônica numa regra, num padrão de medida racional, recusando qualquer hipótese”.

Da hipótese do "estado de natureza" Kant executará a do "contrato", pelo qual o ser humano entrelaça sua vontade à dos demais mediante uma idéia da razão e somente dentro da perspectiva transcendental poderá firmar sua posição de ser político, originando na adesão racional ao contrato o fundamento de legitimidade da racionalidade constitutiva do Estado: o porquê do contrato faz-se colocar devido ao sistema de direitos inerentes ao sujeito e sua pressuposição racional o que deriva, 
portanto, da idéia liberdade como fixação da essência de uma terminologia que se expressa na possibilidade do 'fato da razão' (a liberdade numênica).

Se, portanto, a adesão ao contrato implica adesão a uma idéia e se essa última constrói a racionalidade inerente ao sistema jurídico, uma vez posto o contrato se firmará a obrigatoriedade incondicional de cumpri-lo, o que significa a obediência ao soberano (TERRA, 1995, p.39-40).

O contrato, em Kant, não pode ser considerado um mecanismo político conservador, simplesmente para assegurar a existência do Direito e do Estado burgueses, mas sim um mecanismo de objetivação da razão, onde a capacidade de transformação do cidadão está presente pela idéia de autonomia. Essa forma de organização do poder impulsiona a própria reforma da sociedade burguesa, embora pareça acanhada para críticos como Marcuse (TERRA, 1995, p.42). Terra (1995, p.45) frisa, contra os críticos, 'A própria concepção da liberdade exige a participação do povo na elaboração das leis, o que o torna soberano.'

Se a racionalidade humana se desenvolve consoante a liberdade para seguir seu caminho ético, ela deve ser considerada o valor supremo, como Kant (2008) coloca na "Fundamentação". Como diz Terra (1995, p.160) com apoio em Guéroult, para Kant o homem é ao mesmo tempo um ser racional livre e um ser sensível portador de inclinações.

Assim, a construção da racionalidade da vontade implica reconhecer a idéia da liberdade é uma propriedade da vontade, e a autonomia a capacidade humana de se conceder leis o que caracteriza a noção de um sujeito autônomo, que funda tanto a realidade moral como a jurídica.

O valor da liberdade emerge como central na filosofia kantiana e deve ser protegido juridicamente, conforme aponta Terra (1995, p.133). A liberdade como autonomia interna incondicionada do sujeito implica a finalidade inalienável da vontade, a qual se se dirige a objetos externos à consciência é força de fundação do mundo jurídico enquanto parte do mundo ético.

Pelo menos esse direito à autonomia deve ser a priori protegido à interferência estatal, para a coerência de um raciocínio político kantianamente pautado, decorrente da natureza da razão objetiva, da idéia da liberdade e da universalidade da lei moral, pois se o Estado não pode desrespeitar a dignidade, igualmente não deve prescindir do respeito à autonomia. 
As diferenciações da liberdade política em Kant (2006, p.27) são, pois, passagens do domínio de liberdade interna para o da autonomia moral e, por conseguinte, para o de independência cidadã.

A fundamentação da democracia em Kant (2008, p.23) dá-se através do uso público da razão como expressão da emancipação humana, tanto pelo sábio como por qualquer do povo.

O fundamento do Estado de Direito é a lei, entendida como contrato de vontade das partes. E qual o fundamento da vontade das partes ? A liberdade interna entendida primeiramente como liberdade moral e, conseguintemente, como liberdade jurídica (quando dirigida a objetos externos à consciência).

$\mathrm{Na}$ defesa da liberdade interna intangível, pela união entre liberdade interna e lei moral categórica, Kant vai além de Rousseau enquanto teórico da democracia, pois uma das possibilidades da teoria democrática radical do genebrino seria a tirania da maioria, em um governo antiético.

A liberdade interna é sempre o ponto de partida dos atos éticos, irredutível e, por isso mesmo, a priori à ação do Estado. Assim, no âmbito interno do sistema kantiano de uma autonomia inteligível que, se se manifesta como imperativo categórico (assegurada na possibilidade de realização da lei moral), deve se manifestar também como direito $a$ priori a todo o direito positivado, devendo por este ser encampado e protegido.

A autonomia da vontade na Modernidade foi assombrada, mas visceralmente dependente (como até na atualidade) com o poder do "Leviatã" estatal, como proclamou Thomas Hobbes (1979, p.34).

O idealismo objetivo de Hegel concebeu o indivíduo como mero instrumento nas mãos do Estado, a fim de realizar o Espírito Absoluto. Isso marcou profundamente sua obra como um reforço ao nacionalismo, coletivismo e estatismo a ele posteriores.

O mercado globalizado 'coisifica' o ser humano, transforma-o em mercadoria e dissolve a individualidade em um conjunto de expressões de comportamento observáveis a fim de se enquadrar em certas funções do sistema.

Os materialismos hobbesiano e freudiano consideraram incoerente o indivíduo e sua existência singular como mero apêndice dos processos de poder social que geram traumas básicos sobre a personalidade individual que a impedem de ser efetivamente 'livre'. 
O que há de comum nos diversos ataques à autonomia humana é o não saber olhar adiante das contingências históricas que condicionam a individualidade que deve ser valorizada em si, pois seu corolário maior é a proteção da liberdade.

Sob as precárias condições de existência do indivíduo livre na sociedade atual, há necessidade de reconhecer em cada época histórica esse incondicional imperativo da liberdade como possibilidade de toda ética.

Partindo de Kant, Ricardo Terra coloca que o cerne da liberdade é a autonomia, fundamento da própria dignidade do sujeito, inderrogável pelas leis do Estado positivo e histórico; autonomia diante dos outros e do coletivo; autonomia como ausência de imposições sobre o indivíduo, no sentido de não intervenção na vida privada e na personalidade (concepção liberal-individualista), e não dominação por poderes políticos externos (concepção republicana).

Para Terra o valor da propriedade decorre da quebra da violência inerente ao "estado natural" e da fundação do "estado civil", colocando a liberdade de posse como fundamentada na lei (TERRA, 195, p.132); liberdade e igualdade são condições necessárias para a vida jurídica, desde a posse provada através da lei até a participação pública.

O bem comum é o bem da República entendido como governo constitucional; assim, a força da virtude pública está em encontrar um fundamento da ação do cidadão na proteção legal em função do prescrito constitucionalmente. Assim, Terra (1995, p.133) sintetiza a adequação de Kant a valores básicos:

Liberdade (aspecto do liberalismo individualista); essa liberdade consiste na participação cívica; na autonomia pública de contestar publicamente; de ser proprietário, valor da livre iniciativa econômica, com o qual Kant, dessa forma, confirma seu liberalismo (TERRA, 1995, p.135).

Igualdade, com os aspectos da garantida por lei, posto que cada membro possui direito de coação sobre outro, e no aspecto da igualdade dentro da lei, de ser tratado com equidade por todos os outros e pelo Estado (TERRA, 1995, p.134).

Independência (de cada homem) como cidadão, de participar da vida do Estado dentro dos ditames da lei, "diz respeito à participação na legislação, tendo direito de voto - os cidadãos que são co-legisladores (TERRA, 1995, p. 135)”.

Bem comum enquanto valor fundamental de adequação à constitucionalidade e a legalidade, afeito ao bem da República (TERRA, 1995, p. 135); 
Publicidade, pois todo o Direito construído sem transparência perde a noção de legitimidade e de democracia, tendo o povo de fiscalizar o Estado e participar da formação da lei (TERRA, 1995, p.174.)

Democracia, dentro do governo constitucional; o poder legislativo é o principal valor político, pois dos três poderes que formam a instituição republicana, o legislativo é o principal - tendo um valor intrínseco superior aos demais porque a representação democrática é a base da legitimação política (TERRA, 1995, p.61).

Paz, expressa na 'À Paz Perpétua' como o objetivo de um direito cosmopolita a qual se adequariam os povos de uma maneira progressiva dentro da evolução das instituições internacionais de proteção do Direito Internacional (TERRA, 1995, p.57).

Laicidade, pois todo Estado republicano é laico e não pode proteger sobre as demais qualquer religião nem propugnar um bem comum que não esteja no âmbito da lei (TERRA, 1995, p.56).

Patriotismo, pois todo cidadão deve buscar o bem comum de seu Estado enquanto dever cívico (TERRA, 1995, p.57).

Justiça Distributiva Pública, pois o Estado tem o dever de cobrar impostos e de aplicar a lei penal em favor do bem da maioria (TERRA, 1995, p.54).

Ordem, respeito às leis públicas dentro da soberania constitucional do Estado;

Busca da felicidade, desde que não fira a liberdade dos outros (a própria colimitação das liberdades é a expressão do conceito kantiano de Direito).

Sintetizando todos os valores, porém, para Kant, conforme Terra (1995, p.134), possuem a liberdade e a igualdade uma importância central, capazes de suster a justiça constitucional em uma República.

Percebe-se, conclusivamente, que se o espaço público do Estado na pósmodernidade está ameaçado de um esvaziamento de sentido, o que em parte se coliga à crise da vivência de valores, subjetivados no processo de relativização crescente na sociedade pós-industrial, é preciso uma teoria que resgate não apenas os canais do conhecimento intersubjetivo, porém a forma pública do processo de comunicação.

Nesse modo, faz-se necessário que uma teoria do provimento público de forma jurídica seja colocada a lume, assim, é em Kant que se encontra das vias de resgate dos valores e do discurso democráticos, posto que assegura com sua teoria a primazia de posição do sujeito na arena pública, colocando-o em função da capacidade de participação e de fiscalização públicas, ao passo que, quanto ao problema dos valores, põe à disposição do sujeito como cidadão uma valorização em si (autonomia e 
dignidade a priori a todo o pacto) e dota a teoria jurídico-política de valores formais universais para todo o processo político (republicanismo, liberdade, paz, bem comum, igualdade, patriotismo, justiça pública, publicidade, laicidade, etc.), valores esses que podem ser objetados a um Estado autocrático ou despótico e que, como não possuem conteúdos imutáveis de essências metafísicas (Kant já criticara radicalmente as pretensões de absolutidade metafísica nas três Críticas) podem ser reconstruídos discursivamente pelos sujeitos em um espaço democrático.

Creio que Terra deixa esses paradigmas bem claros em sua obra e tal ganho em termos de análise da filosofia política de Kant tem muito a contribuir para a crise da Democracia e do espaço publico brasileiros, ofertando uma alternativa importante ao debate político nacional.

4. Kant no Brasil: significações política e jurídica

Miguel Reale (1949, p.6-7) historiou a recepção do pensamento kantiano no Brasil, sua obra é uma referência interessante, embora pouco conhecida do conjunto da escrita global do jusfilósofo paulistano. O fato é, segundo Reale, que jusfilósofos leram Kant no Brasil desde a proclamação da República até a atualidade extraindo elementos ora ortodoxos (Lafayette Pereira), ora mesclados com outros filósofos como Krause e Spinoza; Tobias Barreto criticou a filosofia de Hegel e realizou uma volta a Kant; a própria "Escola do Recife" o grande celeiro filosófico-cultural e jurídico até início do século XX, deixou-se influenciar por Kant quanto aos aspectos da valorização da empiria e da metodologia, embora preferindo o positivismo naturalista de matriz francesa (comteana) como método base de investigação da cientificidade do Direito.

No geral, porém, com apoio na autoridade histórica de Clóvis Bevilaqua, o grande jurista positivista da primeira metade do século XX e cultor da história do Direito e da Filosofia no Brasil, Reale (1949,p.8) considera tímida a percepção do pensamento kantiano no Brasil. Clóvis é o típico representante do gosto tradicional da elite jurídica brasileira por Filosofia, ele é a síntese e um dos melhores representantes da Filosofia feita por não filósofos no Brasil até a criação das Universidades a partir da década de trinta do século anterior e a instauração no país das Faculdades de Filosofia, a chegada de docentes estrangeiros que incrementaram e cientificizaram a pesquisa filosófica brasileira a partir da metade do século XX, retirando a primazia do diletantismo filosófico dos juristas. 
Desse modo, pode-se perceber que o movimento kantiano no Brasil efetivamente encontra força a partir das décadas de 70 e 80 do século XX. Atualmente é uma das mais fortes vertentes no pensamento filosófico nacional. $\mathrm{O}$ desafio atual é a possibilidade de realizar-se um diálogo mais profícuo entre Direito, Política e Filosofia, perfazendo um acréscimo qualitativo no debate jurídico e político brasileiro, é de se esperar que a matriz de pensamento kantiano deve ofertar diversos caminhos, basta ver a forte influência no Brasil de autores de inspiração kantiana tais como Bobbio, Habermas, Dworkin, Rawls etc., o que ocasiona um intenso debate e sofisticação intelectual para o Direito, especialmente nas disciplinas propedêuticas e no Direito Constitucional.

O papel racional de unificação dos processos cognitivos e de superação das dicotomias de valores em conflito no campo jurídico pode ser desempenhado por um kantismo renovado que recomece pelo aspecto de uma defesa da argumentação como ponto de fusão entre pretensões de validade universal de discursos de legitimação e capacidade de absorção pelo Direito de tais discursos. Nesse aspecto a função integradora da razão kantiana propicia os elementos da teleologia crítica de cada sujeito - a capacidade de cada qual defender argumentativamente suas pretensões de valor no espaço público, e do Direito racional como meta republicana e igualitária das condições de liberdade juspolítica, como meios de reflexão sobre o que as pretensões de validade dos discursos exarados pelos sujeitos podem ofertar ao Direito. Não apenas como metafísica os valores enriquecem o Direito enquanto metas supra normativas a atingir, mas como objetos de uma verdade construída pela razão e pela despotencialização dos conflitos no debate racional público como ideou Kant.

\section{Referências}

CASSIRER, Ernst. O Mito do Estado. Lisboa: Europa-América, 1961.

COSTAS DOUZINAS. O fim dos direitos humanos. São Leopoldo: Unisinos, 2010.

KANT, Immanuel. A metafísica dos costumes. Porto: Calouste-Gulbenkian, 2005. . Antropologia de um ponto de vista pragmático. São Paulo: Iluminuras, 2009. . À Paz Perpétua. Porto Alegre: L \& PM Pocket, 2010.

. Fundamentação da Metafísica dos Costumes. Lisboa: Edições 70, 2008. 
- Teoría y Prática. Em torno al tópico: tal vez eso sea correcto em teoria, pero no sirve para la practica; Sobre um presunto derecho de mentir por filantropia. Madrid: Tecnos, 2006.

HESSEN, Jonhannes. Filosofia dos Valores. Coimbra : Armênio Amado, 1980.

HOBBES, Thomas. Leviatã ou matéria, forma e poder de um Estado eclesiástico e civil. São Paulo: Abril Cultural, 1979.

HUMBOLDT, Wilhelm Von. Los limites de la acción del Estado. Madrid: Tecnos, 2002.

HUME, David. Tratado Sobre a Natureza Humana. As circunstâncias de justiça. In: MAFFETONE E VECA (Orgs.). A idéia de justiça de Platão a Rawls. São Paulo: Martins Fontes, 2005.

PEREZ, Daniel Omar. (Coord.). Ensaios de ética e política: Maquiavel, Hobbes, Rousseau, Kant, Wittgenstein. Cascavel: Edunioeste, 2002.

RADBRUCH, Gustav. Leyes que no son Derecho y Derecho por encima de las leyes. In: Derecho Injusto y Derecho Nulo. Madrid: Aguillar, 1971.

REALE, Miguel. A Doutrina de Kant no Brasil. São Paulo: s/e, 1949.

ROHDEN, Valério (Coord.). Kant e a instituição da paz. Porto Alegre, 1997.

TERRA, Ricardo. A política tensa. Idéia e realidade na filosofia da história de Kant. São Paulo: Fapesp, 1995. 